University of Maryland Francis King Carey School of Law

DigitalCommons@UM Carey Law

$1-1-1993$

\title{
The Law's Response to Reproductive Genetic Testing: Questioning Assumptions about Choice, Causation and Control
}

Karen H. Rothenberg

University of Maryland School of Law, krothenberg@law.umaryland.edu

Follow this and additional works at: https://digitalcommons.law.umaryland.edu/fac_pubs

Part of the Bioethics and Medical Ethics Commons, and the Health Law and Policy Commons

\section{Digital Commons Citation}

Rothenberg, Karen H., "The Law's Response to Reproductive Genetic Testing: Questioning Assumptions about Choice, Causation and Control" (1993). Faculty Scholarship. 159.

https://digitalcommons.law.umaryland.edu/fac_pubs/159

This Article is brought to you for free and open access by the Francis King Carey School of Law Faculty at DigitalCommons@UM Carey Law. It has been accepted for inclusion in Faculty Scholarship by an authorized administrator of DigitalCommons@UM Carey Law. For more information, please contact smccarty@law.umaryland.edu. 
Karen H. Rothenberg

Professor of Law. Director.

Law and Health Care Program.

University of Maryland. School of

Law, Baltimore. Md.. USA

\section{The Law's Response to Reproductive Genetic Testing: Questioning Assumptions about Choice, Causation and Control}

\begin{abstract}
The law's response to reproductive genetic testing depends on a number of assumptions about choice, causation and control which need to be questioned. From the preconception stage forward, the illusion of choice may raise such fundamental questions as the woman's choice not to be tested. limits on genetic information, and the availability of reproductive options. In turn, assumptions about choice raise questions about the responsibility for results and the connection between choice and causation in the context of wrongful birth and life actions. Assumptions made about control over reproductive choice and over causing 'harm', will impact on the development of future law.
\end{abstract}

The law's response to reproductive genetic testing depends on a number of assumptions. It is time to reexamine assumptions that have shaped the expansion of reproductive genetic testing. This paper explores and questions assumptions made about the three ' $\mathrm{Cs}$ ' choice, causation and control.

\section{Choice}

Reproductive genetic testing assumes choice. The choice to become pregnant or the choice to forego pregnancy. The choice to have a test or not to have a test. The choice to decide what to know or what not to know. The choice to live with uncertainty or the choice to know for certain. The choice to carry a pregnancy to term or the choice to terminate the pregnancy.

The legal and ethical principles that drive the debate in reproductive generic testing depend on the model of patient autonomy, right to privacy and choice. Nondirective counseling and the informed-consent process are based on our assumption that patient choice is given. Proponents of reproductive genetic testing argue that with more genetic information there will be more choice.

But choice is not that simple. From the preconception stage forward, the illusion of
Karen H. Rothenbere, JD. MPA

Professor of Law

University of Maryland School of Law

$500 \mathrm{~W}$. Baltimore st.

Balimore. MD 21201-1786 (USA)
S. Karet AG. Basei

$1015-3837 / 931$ $0087-0160 \$ 2.75 / 0$ 
choice may raise fundamental questions. I will highlight problems from preconception through birth that should shake our security over choice. Throughout this discussion it is important to point out that, for those women who have little or no access to prenatal care, genetic services are not available. For these women choice is not an option.

(1) In the ideal world. carrier screening prior to pregnancy is a joint responsibility of the couple. Obtaining information about probabilities of genetic risk may help to clarify decision making about reproduction. This is a shared responsibility. However, once the decision is made to conceive with genetically linked sperm and egg, the responsibility shifts exclusively to the woman. This is so even if she is not the carrier of the risky genetic link. The decision to conceive. often tied to the need for genetic connection. shifts all genetic testing to the woman. She is the sole subject of testing. In this context, does she have a choice not to be tested? If she consented to preconception testing, does she have a choice not to be tested once pregnant? Has she waived her right to take her chances?

(2) Most genetic testing is done on women only during pregnancy. Men are yet to experience as a group the impact of such a massive screening effort. As testing becomes incorporated into prenatal care practice, are women presented with the choice to refuse such testing? Providers, who set the standard of care, may feel they do not even have the option to give women a choice. Is it the fear of liability that makes providers believe that they must provide genetic testing without discussing options with the pregnant woman? Yet if choice is our guiding principle, providers have the duty to set out the choices for testing, not just order tests without thought. Ironically, the more the profession buys into the expansion of genetic testing and increases consumer expectations. the more trapped the profession will become into providing the services. The profession has the power and the responsibility to question the risks and benefits of genetic testing in the broader context of comprehensive pregnancy care. and in educating the population as to how infrequently genetic abnormalities contribute to the less than perfect baby.

(3) If a woman makes an informed choice to be tested. can she place limits on the information she wants to know? If not. she must be told ahead of time what conditions are being tested for and the limitations, if any, to test results. It would appear that a woman's choice to be tested need not prevent her from waiving knowledge about certain types of genetic information.

(4) Conflict of interest can impact on choice. Genetic counseling should not be a risk management session scheduled just prior to genetic testing in which the woman signs an informed consent form. Rather there should be separation between counseling and procedures. Genetic counseling is a process separate and apart from testing. Genetic counselors should not feel that they have failed themseives or their employers if a woman chooses not to be tested. But that can often be the financial result. In this situation the woman may only have the illusion of choice by participating in a genetic counseling session just prior to a scheduled test.

(5) During genetic counseling it must be clear what options a woman will have after receiving test results. Obviously. there is increasing concern that. as genetic testing is expanding, the constitutional right to choose to terminate a pregnancy is contracting. The Webster [1] decision makes it more likely that each state will set its own rules for categorizing what conditions justify abortion. Some states will allow abortion for 'fetal defect', congenital anomalies and the like. but as reproductive testing increases how will abor- 
tion legislation adjust? Such state law variation will require woman and providers in each state to adjust accordingly. For the future of reproductive genetic testing very much depends on the future of the right to choose.

Furthermore, the Rust [2] decision confirms that the federal government may allow limits on the content of disclosure about abortion in family planning programs. Even if some assume that medically indicated abortion may be discussed under certain conditions, it is clear that the Rust climate of silencing providers will further limit choice for the poor, particulariy with respect to disclosure on genetic testing and abortion services. Legal confusion often breeds further access problems for women. In fact. a number of states have inconsistent laws and public policies which may fund genetic services but not abortion.

(6) In addition to such barriers, the profession is responsible in practice for limiting choice by abandoning the care of the pregnant woman midstream. The medical profession needs to assure that either the providers making the referral for genetic testing or those offering the genetic testing procedures provide for abortion services. The medical profession needs to better coordinate such services for the woman. At a time when training in genetic testing is expanding, training in abortion services among residency programs is decreasing. Without such continuity, the provider is in fact limiting choice for the woman.

(7) Some women feel they have no choice but to abort because there is insufficient information on prognosis. quality of life and services for the disabled. And do those women who do not abort waive future support for children born with disabilities? This fear may be real as we hear reports of insurance companies and health maintenance organizations who threaten not to cover expenses for children born by choice with genetic disorders.

\section{Causation}

With choice comes responsibility for results. Reproductive genetic testing assumes a cause and effect. But causation in this context is very confusing. The questions raised by wrongful-birth and wrongful-life actions may help illustrate the connection between choice and causation.

The wrongful-birth action assumes that. because the provider failed to disclose information about genetic testing. or failed to provide the correct test result. the provider caused a harm that requires compensation to the mother (or parents) of a child born with a genetic disorder. The harm is not that the child was born with a genetic disorder. Rather. the harm is that the mother was deprived of the right to know about a testable genetic condition and then could not exercise her right to choose whether to terminate the pregnancy. Obviously, if choice was not at issue. there might be no causation between the provider's negligence and the harm.

On the other hand. most courts have been a lot less willing to recognize a wrongful-life action brought by a child born with a genetic disorder against the provider for the same negligent conduct. In this case. some courts cannot find a causal link. The provider does not have a 'duty to rescue' the fetus from being born. And what is in fact the harm to be compensated? To establish such a duty might require the court to value nonexistence over a life with disability. As noted above. the failure to provide genetic testing, for example. did not cause the genetic condition. And in this case. the provider is not depriving the child of a choice. In utero, the fetus did not have the choice to make.

Of course, the courts have made assumptions about both choice and causation. In this context. could women (and parents) have a 'duty to rescue" a fetus from being born with 
disabilities? Does a woman have both a legal duty to discover genetic traits and to act to prevent the fetus from being born with a genetic disorder? At least one commentator has also characterized the failure to be tested (and to abort a fetus with a genetic disorder) as analogous to fetal or child abuse. To date, a few states. rejecting such a legal duty, specifically provide that there is no such action recognized under state law.

Yet there has been a trend in other areas of maternal behavior to draw connections between maternal behavior and predictions that such behavior caused harm to the fetus. Threats of child abuse. criminal prosecutions and tor liability have been raised against women. for example, who use drugs and alcohol during pregnancy. Once we pinpoint blame on pregnant women for causing 'bad outcomes'. are we on a slippery slope? Particularly if we assume women have choices, some may argue that we should assign causal responsibility for women who give birth to children with genetic disorders.

\section{Comtrol}

Ultimately, the expansion of reproductive genetic testing will be about control. Control over what choices get made. who makes them, and who judges them will directly influence how we shape to law's response. The assumptions we make about control over reproductive choice. and control over causing or preventing 'harm'. will impact on the development of future law. Will providers of genetic testing determine what genetic information is relevant to be tested for and disclosed in carrier screening programs and to pregnant women? What limitations will the government place on the access to such information? What control will there be between access to genetic services. abortion services and/or support services for families and children with disabilities? What increase in control will laws give the medical profession to define 'fetal defect' and medical necessity for 'responsible' limits on abortion. Will the expansion in genetic testing also signal the remedicalization of abortion as a social welfare or public health strategy? What control will the law maintain over a woman's right to conceive without prior genetic information and to carry a pregnancy to term without genetic testing?

These questions do not have easy answers. Both providers and consumers must recognize that there are limits on control. Most importantly. we cannot assume that we can control a pregnancy outcome. The expansion of genetic testing may assume we can, but in the end we must recognize that conditions beyond our knowledge or grasp may cause outcomes that we cannot control. Certainly law cannot change this reality. Once we rèalize this fact we may be more willing to question our assumptions and accept our limitations.

\footnotetext{
References I Webster v. Reproductive Health Services. 492 US 490 (1989).

2 Rust v. Sullivan. 111 S.Ct. $17 \$ 9$ (1991).
} 